\title{
Through the Viewfinder: Positive Exposure a Year Later
}

\section{ERICA J. SUTTON, LAUREN ROSAPEP, KAREN BALL, MEGAN TRUITT, BARBARA BIESECKER,* RICK GUIDOTTI, AND DIANE MCLEAN}

Positive Exposure, a non-profit organization founded and directed by former fashion photographer Rick Guidotti and co-directed by psychiatrist Dr. Diane McLean, uses photography and video interviews to explore the lived experiences of people affected with genetic conditions. Positive Exposure challenges pervasive social biases and stereotypes about genetic variation and strives to broaden and enrich societal perceptions of human beauty and spirit. Presented here are the open-ended personal reflections completed by four individuals with craniofacial differences recruited from a support group, Inner Faces. These four case studies aim to relay the professional photo-shoot experiences of people who may be challenged by the stigma associated with craniofacial differences. Questions addressed issues of perceived self-esteem, stigma, hopefulness, and photography experiences. These personal reflections were gathered 1 year following participation in a Positive Exposure photo-shoot. Participants described the ways in which the photo-shoot has been a lasting and life-promoting experience. In addition, these individuals emphasize the integral and enduring role the photographer, Rick Guidotti, played in their personal awakening. Positive Exposure provided these individuals with renewed identification of both inner and outer sources of beauty. These four case studies suggest that Positive Exposure may serve as a sustainable intervention to bolster self-esteem and self-image. Published 2006 Wiley-Liss, Inc. $^{\dagger}$

KEY WORDS: Positive Exposure; photography; craniofacial conditions; self-esteem; stigma

\section{How to cite this article: Sutton EJ, Rosapep L, Ball K, Truitt M, Biesecker B, Guidotti R, McLean D. 2006. Through the viewfinder: Positive Exposure a year later. Am J Med Genet Part C Semin Med Genet 142C:260-268.}

\section{INTRODUCTION}

Historically, photography has been used in the clinical setting predominantly to capture the physical and mental illnesses of patients. Recorded photographic images of medical conditions aid health care providers in their study of disease etiology, course, and treatment effects [Phillips, 1986; Jones, 1996]. The medical photographic process, however, can be uncomfortable, humiliating, and alienating for the exposed patients [Jones, 1996]. The stark photographs published in medical textbooks and journals not only depict medical conditions but also capture patients' vulnerability [Jones, 1996]. Although the

Barbara Biesecker, Rick Guidotti, Diane McLean, Share senior authorship of this paper.

Erica J. Sutton is a Research Associate at The New Women's College Hospital and a doctoral candidate in the Department of Public Health Sciences and Joint Centre for Bioethics at the University of Toronto, Ontario, Canada. She was a research fellow in the Social and Behavioral Research Branch, National Human Genome Research Institute, National Institutes of Health. Ms. Sutton's dissertation addresses ethical issues related to mandatory expanded newborn screening programs.

Lauren Rosapep is a research fellow at The William and Flora Hewlett Foundation. She was a research fellow in the Social and Behavioral Research Branch, National Human Genome Research Institute, National Institutes of Health. Ms. Rosapep's research interests are in the impact of US food and agricultural policies on global poverty alleviation.

Karen L. Ball is President and CEO of the Sturge-Weber Foundation in Mt. Freedom, New Jersey. The mission of the Foundation is to further research and clinical care for individuals affected with Sturge Weber Syndrome and their families. Ms. Ball is interested in research aimed at instilling a positive self-image among individuals with Sturge-Weber and in promoting the role of advocates in research.

Megan Truitt is a graduate student in the JHU/NHGRI Genetic Counseling Program and twice served as a summer research fellow for the Social and Behavioral Research Branch, National Human Genome Research Institute, National Institutes of Health. Ms. Truitt is interested in research on psychological models of genetic counseling.

Barbara B. Biesecker is a genetic counselor and Head of the Genetics Services Unit, Social and Behavioral Research Branch, National Human Genome Research Institute, National Institutes of Health. She is also Director of the JHU/NHGRI Genetic Counseling Program. Ms. Biesecker's unit studies the effectiveness of genetic counseling interventions and the quality of life for individuals living with genetic conditions.

Rick Guidotti is a former fashion photographer and Director of Positive Exposure, Inc. a nonprofit organization whose innovative program challenges the stigma associated with difference and celebrates the richness of genetic variation with positive images and powerful life stories.

Diane McLean, is a resident in psychiatry at Columbia University Hospital in New York City, New York. She is also Co-Director of Positive Exposure, Inc. Dr. McLean's research interests include factors associated with the high rates of preterm delivery among black women in the United States, and in exploring the lives of those living with visible difference and instilling hope.

Grant sponsor: Intramural Research Program of the National Human Genome Research Institute; Grant sponsor: National Institutes of Health

${ }^{*}$ Correspondence to: Barbara Biesecker, M.Sc., NHGRI/NIH, 10 Center Drive (10/10C101), Bethesda, MD 20892-1852.

E-mail: barbarab@mail.nih.gov

DOI 10.1002/ajmg.c.30113

Published 2006 Wiley-Liss, Inc.

This article is a US Government work and, as such, is in the public domain in the United States of America. 


\section{The medical photographic} process, however, can be uncomfortable, humiliating, and alienating for the exposed patients. The stark photographs published in medical textbooks and journals not only depict medical conditions but also capture patients' vulnerability.

interest in and practice of clinical medical photography for teaching purposes persists, health care professionals are discovering additional uses for and benefits of photography in the health care arena.

Photographic interviews, photoessays and photo analysis are among the latest uses of photography in the clinical setting, particularly among nurses, psychologists, and psychiatrists [Phillips, 1986; Highley and Ferentz, 1989; Hagedorn, 1990; Dollinger, 2002]. For example, a patient might be asked to take pictures of his or her experience with illness over time, both inside and outside of the hospital, as a form of storytelling [Highley and Ferentz, 1989; Hagedorn, 1990]. A psychiatrist might ask a patient with mental illness to take photographs or collect past photographs that define who they are-a process that can offer insight into a patient's past and/or present realities [Phillips, 1986]. Beyond telling a story, the interactive use of photography in clinical settings also facilitates communication between patients and their family, friends, and health care providers [Phillips, 1986; Weiser, 1988; Highley and Ferentz, 1989; Hagedorn, 1990].

The practice of using photography to offer insight into the lived experiences of health and illness is often categorized as photo-therapy or therapeutic photography [Weiser, 1988]. Photo-therapy typically occurs within a formal counseling (patient-therapist) setting whereas therapeutic photography is a "self- initiated" personal, introspective exploration which may include a facilitator but does not involve a trained therapist who systematically guides the process [Weiser, 1988]. Although both are distinct fields designed to help individuals work through personal challenges, there is overlap, as sometimes the process of therapeutic photography may evoke emotions that could benefit from the professional guidance and counseling offered with photo-therapy [Weiser, 1988].

Photo-therapy and therapeutic photography techniques include inviting the patient/client/participant to assume the role of photographer to take self-portraits and pictures of other people, places and things. Some approaches include professional photography sessions whereby the patient/ client/participant is photographed. Other strategies may include weaving a history through the use of existing and selectively chosen photographs [Phillips, 1986; Weiser, 1988, 2005; DeMarre, 2004; Ellison, 2005]. Currently, professional photo-shoots are used in phototherapy sessions of individuals suffering from anorexia, physical abuse, and women in search of their inner beauty and strength [DeMarre, 2004; Ellison, 2005].

Positive Exposure, a non-profit organization in New York City, engages in photography in combination with videography as a distinct and innovative means of challenging existing social

\section{Positive Exposure, a non-profit organization in New York City, engages in photography in combination with videography as a distinct and innovative means of challenging existing social prejudices and fears associated with genetic differences, distinct from photo-therapy.}

prejudices and fears associated with genetic differences, distinct from photo-therapy. Professional photoshoots, coupled with in-depth personal interviews, aim to empower people living with genetic conditions by fostering positive self-esteem, sense of personal agency and hopefulness for the future. These media serve as vehicles through which children and adults from all over the world can share their lived experiences-a process that anecdotally corroborates the claim that photography and personal reflection are helpful healing mechanisms [Dollinger, 2002].

Positive Exposure's combined use of professional photo-shoots and video interviews is a unique way to address issues such as self-esteem, body image and feelings of social awkwardness and anxiety in individuals with physical differences. We are currently undertaking a study that systematically explores the potential long-term benefits of these professional photo-shoots for individuals with craniofacial conditions, a population that has previously reported low self-esteem, negative body image, and/or social awkwardness [Kapp-Simon et al., 1992; Kapp-Simon, 1995; Pope and Ward, 1997a,b; Sarwer et al., 1999; Kelton, 2001]. We plan to describe both quantitatively and qualitatively the use of professional photoshoots for improving self-perceptions among a potentially stigmatized population. Here we present four pilot case studies that support the potential for the long-standing positive benefits of Positive Exposure.

To the best of our knowledge, our ongoing study promises to be the first study to explore and describe the effects of professional photo-shoots on individuals with rare genetic conditions. The case studies presented below are a prelude to the larger study currently underway to investigate the use of professional photo-shoots and video interviews as an intervention. This article describes the potential long-term impact of Positive Exposure photoshoots on individuals with craniofacial conditions. The personal reflections, obtained 1 year after the photos were 
taken, suggest sustained effects from the photo-shoot experience.

\section{METHODS}

\section{Study Design}

The National Human Genome Research Institute of the National Institutes of Health collaborated with Positive Exposure on this IRB approved pilot endeavor to a more elaborate parent study underway. In the Spring of 2004, Positive Exposure joined forces with Inner Faces, a support network for children and young adults with such conditions as isolated cleft lip and palate, hemifacial microsomia, Mobius syndrome, Apert syndrome, and Treacher Collins syndrome, to increase social awareness of facial differences. Inner Faces is the youth group within Forward Face, an organization based in New York that provides children and their families with resources available to help them navigate the medical and often psychosocial challenges associated with craniofacial conditions. As part of an awareness campaign, ten members of Inner Faces participated in a professional photoshoot with Rick Guidotti in his Manhattan photography studio. Of the ten individuals that participated in the Inner Faces/Positive Exposure initiative, four responded to our recruitment flyer and volunteered to participate in our pilot efforts. The other six all responded willingly but never returned the personal reflections despite several reminders sent to them by e-mail. The team knows all six participants and there were no striking characteristics of the four who followed through in contrast to those who did not.

Each volunteer received and completed a self-administered survey comprised of open-ended questions addressing issues of self-esteem, stigma, and hope, standard questions to ascertain socio-demographic information, and short-answer questions pertaining to their craniofacial diagnosis. The openended questions required participants to reflect on both personal and societal perceptions of attractiveness; how others perceive them; how they feel about themselves; and how they feel about having their photograph taken and seeing themselves in pictures. They were asked for their advice to others affected with the same condition. Participants were also asked to describe their photoshoot experience with Rick Guidotti and to relay their feelings and reactions immediately following the photo-shoot and 1 year later.

\section{Description of the Photo-Shoot Format}

The structure of the Positive Exposure photographic experience was developed for portability and use in different locations. The Positive Exposure team has traveled extensively around the globe and has developed a portable photographic formula that is uniformly fun, welcoming and nurturing. Photoshoot locations are accessible and nonintrusive. By utilizing available natural light rather than "high-tech" lighting equipment, participants can react solely to the photographer and camera without superfluous distractions. The portable nature of the project creates consistency in each of the participant experiences regardless of the photoshoot location.

The photography session is carefully designed to unleash the spirit of the individual photographed, providing the opportunity to celebrate individuality and uniqueness. The atmosphere of a photo shoot is a nurturing one, creating a safe environment for the participant to relax and feel comfortable. The basic tenets of every shoot include the establishment of a professional relationship characterized by respect, feelings of safety and trust, good eye contact, genuineness, warmth, compassion and a sensitivity for each individual's concerns, fears and strengths. Rick creates an atmosphere of empathic understanding.

Each photo-shoot begins with a dialogue between Rick Guidotti and the participant to establish rapport. The conversation centers on the participant and his or her interests. Any worries, insecurities or concerns the participant may have about being photographed are directly addressed. Rick Guidotti proceeds to photograph, always with reinforcing, reassuring and positive language, utilizing phrases and words like "YOU'RE GORGEOUS," "YOU'RE AMAZING" "UNBELIEVABLE," "SPECTACULAR," "FANTASTIC." These exclamations come from Rick's personal values and beliefs that everyone deserves to hear them about themselves, to uncover what makes them beautiful and to realize their own unique beauty. This is Rick's philosophy and style as an artist.

The photographic session provides the atmosphere for the participant to appreciate and celebrate his or her differences, reinforcing the participant's inner and outward beauty. The participant is not posed but is encouraged to be spontaneous and relaxed, even to move around and laugh, depending upon how they are feeling. The participant begins the process of creating a new self-image or allowing a hidden image to emerge as reflected through a positive and lifeaffirming lens. The sessions are flexible in order to encourage the creativity of the participant who may choose to pose or even to create a certain mood with Rick's expert direction. His direction is informed by his 25 years as a fashion photographer.

\section{Data Analysis}

The original codebook for the parent study was based on the personal reflection survey. However, codes were modified based on participants' completed reflections. Data was coded initially by one coder (LR) and double coded in its entirety by a second coder (BBB). Themes were identified and quotations were culled from the data to convey them in the words of the participants. However, given the small number of participants, we present the data as individual case studies rather than as a collection of themes. The cases preserve the context of each individual's life and avert surmising themes on insufficient evidence. 


\section{RESULTS}

\section{Case Study 1}

Socio-Demographics

Age: 38

Sex: Male

Marital status: Single, no children

Education: Post-graduate

Diagnosed condition: Bi-lateral cleft lip/cleft

Membership in a support group for condition: No

Illness perception

Perceived overall health: Good

Perceived seriousness of condition on a scale of 1-10: Low (2)

Most challenging aspect of condition: Inability to have further corrective surgeries due to scar tissue

Perceived control over condition on a scale of 1-10: Low (3)

Personal concept of attractiveness

- This participant favors a combination of physical and personality attributes. More specifically, he considers eyes and a sense of humor attractive characteristics

- Arrogance and condescension are personality traits that this participant finds unattractive

- The participant perceives society's concept of beauty as emphasizing an individual's physical attributes

Self-esteem/perceived stigma/hopefulness

- Other people make this participant feel attractive when they appreciate his personality and inner qualities. Conversely, people make him feel badly when they are rude, stare, and/or ignore him

"The closest I have felt to being attractive—when people appreciate and value my personality and sense of humor (but not my body/face)."

- When the participant makes people laugh or gets feedback indicating that other people value his personality, he feels good about himself. When he concentrates on his failures or when other people react negatively toward him, he feels badly about himself

- This participant generally likes having his picture taken, although sometimes he does not like how he looks in pictures

- On the whole, this participant is not happy with the state of things in his life, particularly with respect to his personal relationships and his career. He is unsure about his future but hopeful that he can find a more meaningful career and live among people who are more accepting of his condition

"The road will be rough achieving this dream, and I hope that my stubbornness will pay off."

Advice for others with the same condition

- "It is crucial to find and build a network of supportive people that can be your community. This takes time but provides emotional stability and rootedness and belonging."

Open-ended responses to the positive exposure photo-shoot

- The photo-shoot was an exciting experience for this participant. Positive Exposure provided a "safe space" for self-discovery and expression that everyday life does not permit because of its emphasis on the social constructs of conventional beauty. The photoshoot made him feel good about himself, valued, and even sexy

"It was a real release for me-an opportunity to expose the playful, mischievous, sexual, and adventurous side of me. It's hard to do that in a society that tries to suppress that — the revelation of those traits are reserved for normal people."

- The experience immediately after the photo-shoot was euphoric for this participant. He felt better about himself after the photo-shoot because for once his face was being valued

"I was thrilled that someone wanted to take a picture of my face. I felt as if my face was being valued and honoured."

- A year after the photo-shoot with positive exposure, the experience continued to be self-affirming for this participant.

He wrote about experiencing discrimination as a result of his facial condition. Although dealing with social discrimination has always been difficult for him, his photo-shoot experience serves as a strong reminder of his value and potential as an individual

"I have experienced discrimination because of the way I look. It is very disheartening and sometimes difficult to bear the burdens of being different. But the photo-shoot is one of a few positive experiences that remind me of what I can be and accomplish to live a quality of life." 


\section{Case Study 2}

Socio-demographics

Age: 40

Sex: Female

Marital status: Single, no children

Education: Post-graduate

Diagnosed condition: Unilateral cleft lip/cleft palate

Membership in a support group for condition: Yes (Inner faces)

Illness perception

Perceived overall health: Excellent

Perceived seriousness of condition on a scale of 1-10: Moderately low (4)

Most challenging aspect of condition: Dealing with the emotional pain caused by a childhood spent feeling different because of her facial condition

Perceived control over condition on a scale of 1-10: Moderate (5)

Personal concept of attractiveness

- This participant favors personality attributes. She finds people who are passionate, accepting, caring, and positive attractive.

- Insensitivity and rudeness are personality traits this participant finds unattractive

- The participant perceives society's concept of beauty as emphasizing an individual's physical attributes

Self-esteem/perceived stigma/hopefulness

- Other people make this participant feel attractive when they compliment her and demonstrate genuine interest in her strengths, specifically her intellect. Conversely, people make her feel badly when they judge her by her face before getting to know her personality

- When this participant challenges herself, overcomes obstacles, and works hard she feels good about herself. Excelling professionally and exercising also make her feel good. When she feels that she has been lazy, has not challenged herself, or has broken promises she feels badly about herself

- This participant is generally uneasy about her physical appearance, especially when having her photograph taken "Oh boy. Is that really me? It can't be! I'm not like that! Who is that? There's a real disconnect with the person in the photo."

- On the whole, this participant is pleased that she is improving herself even though she is not meeting as many of her personal goals as she would like. She has many aspirations and is hopeful that 1 day she will be in a committed relationship and be able to fully embrace the way she looks

Advice for others with the same condition

- "Try to separate the person from the cleft. Know that you are a unique and amazing and talented person. You are not simply a cleft. There's so much more to you. Gosh it's hard, but it's key you realize that."

Open-ended responses to the positive exposure photo-shoot

- The photo-shoot was an exciting and magical experience for this participant, as it allowed her to feel genuinely beautiful. She explains that Rick played a big role in helping her "discover" the beauty he saw in her

"I always say that Rick has a third eye, like Picasso. He sees so much. So much beauty."

"Rick (dare I say it) turned me into a babe. He knew it was there all along and helped cultivate it!"

- The experience immediately after the photo-shoot was euphoric for this participant. The photo-shoot made her feel confident because someone had captured her beauty

"I've often said that somewhere inside of me is a gorgeous gleaming diamond-it's just that it's covered with years of self-doubt and self-hatred and insecurity and lack of confidence and fear. Rick found my diamond, polished it off and exposed it for all to see-most of all me. I really saw it!"

- A year after the photo-shoot the experience continued to be self-affirming for this participant. She summarizes her experience as being empowered to see herself in a different way. Instead of self-doubt, this participant discovered that she can now see the beauty in herself

"The key thing for me is to keep that day with me. I see it like a great book that you can take off the shelf over and over and return to it like an old friend. Just thinking about it makes me smile. . How for the first time someone found that lost part of ourselves and danced and celebrated with it. Rick opened me up to a new world-a world of possibilities of magic and beauty." 


\section{Case Study 3}

Socio-demographics

Age: 52

Sex: Male

Marital status: Single, no children

Education: Post-graduate

Diagnosed condition: Mobius syndrome

Membership in a support group for condition: Yes (Inner faces)

Illness perception

Perceived overall health: Fair

Perceived seriousness of condition on a scale of 1-10: Moderate (5)

Most challenging aspect of condition: Getting people to look beyond his condition

Perceived control over condition on a scale of 1-10: Moderate (6)

Personal concept of attractiveness

- This participant favors a combination of physical (brunette hair) and personality attributes, although certain personality traits are critical. Specifically, he is attracted to people who are non-judgmental, humorous, expressive, and caring

- People who are judgmental, insensitive, and have a lack of self-respect are unattractive

- This participant perceives society's concept of beauty as emphasizing an individual's physical attributes with a particular focus on individuals who are powerful and able-bodied

Self-esteem/perceived stigma/hopefulness

- Other people make this participant feel attractive when they complement his appearance or take interest in him as a person. When he has helped another person he feels connected to the world. People make him feel badly when they discriminate against him because of his appearance

"Perhaps the most significant observation is that I, to a certain extent, control my own feelings of "attractiveness," of [whether] others' actions have an impact on me, positively and negatively. If I feel internally attractive, then I will respond differently to people than if I was feeling internally unattractive."

- When this participant does things he is passionate about or takes on challenges, he feels good about himself. When he concentrates on his failures he feels badly about himself.

- When looking at pictures of himself he longs to see facial and body expression

- On the whole this participant is pleased with the state of things in his life, regardless of some limiting medical issues. He is optimistic about his future and hopes he can regain control of his health so that he can pick up old hobbies he is passionate about and achieve personal aspirations more easily

Advice for others with the same condition

- "There will be times when it is difficult to be seen and understood for the person that you are. However, it is important that we not lose sight of our own goals and aspirations and worthiness even when others do."

Open-ended responses to the positive exposure photo-shoot

- The photo-shoot was an exciting, magical experience for this participant as it made him feel special and free. The entire experience allowed for self-discovery in that he could express himself in photographs in spite of his condition. This participant explains that Rick's encouragement and skill enhanced the experience and its success

"His [Rick's] posing me in my leather jacket and a fedora was like the bracing of cold water when you jump in the ocean for the first time."

- The experience immediately after the photo-shoot was euphoric for this participant. The process instantly changed his perspective and made him feel very fortunate. He recalled writing to Rick after the photo-shoot:

"You have shaken my world (self) view and I am now en route on this magical journey, seeing others and myself in a new light."

Years ago, upon seeing fashion models, the subject states: "Instead of seeing myself in those clothes, I could only see my disability and that I was unworthy of wearing such outfits and could not possibly give off their attitudes... on the day of the shoot I asked Rick to photograph me as I saw myself if I were a New York Times fashion model. At that point, I came full circle, becoming one with what started out as just beyond my grasp..."

- A year after the photo-shoot, the participant states that the experience functioned as an empowering force that enabled him to see himself in a new light

"[It allowed] me to put to rest some of my demons that I have had about myself. Perhaps they originated outside of me, nevertheless, I keep them alive. . perhaps when there was no reason to. I am more comfortable expressing my pride in my appearance." 


\section{Case Study 4}

Socio-demographics

Age: 27

Sex: Female

Marital status: Single, 1 child

Education: College graduate

Diagnosed condition: Cleft lip/cleft palate, Bite III, Malocclusion

Membership in a support group for condition: Yes (Inner Faces)

Illness perception

Perceived overall health: Excellent

Perceived seriousness of condition on a scale of 1-10: Low (3)

Most challenging aspect of condition: She never had the right surgeon and thus never finished her surgeries

Perceived control over condition on a scale of 1-10: Low (3)

Personal concept of attractiveness

- This participant favors a combination of physical and personality attributes. She finds people with a sense of self-respect more attractive

- People with poor personal hygiene are unattractive to this participant

- This participant maintains that there is not necessarily a societal definition of attractiveness. Rather, such definitions vary depending on each individual

Self-esteem/perceived stigma/hopefulness

- Other people make this participant feel attractive when they compliment the subject and are kind. Conversely, people make her feel badly when they call her names or concentrate on her physical and/or personality weaknesses

- Knowing that she is smart and able to help others makes this participant feel good about herself. She feels badly about herself when people react negatively toward her or when she is conscious of her condition

- This participant generally does not like to have her picture taken because of her facial features

- On the whole this participant's happiness with her life depends on the day. She is apprehensive about the future because she is afraid that her differences will prevent her from advancing both personally and professionally

"Sometimes the future is hopeless and scary...I want to manage a big company and advance economically. And because I look this way

I feel that people will not respect me or what I have to say."

Advice for others with the same condition

- "If someone doesn't like you, just move on to the next person, until you find someone that really respects you."

Open-ended responses to the positive exposure photo-shoot

- The photo-shoot was an enjoyable experience for this participant. Rick's professionalism made her feel as if she were a model. However, she did not like that she could not see or keep her photographs right after the session

- Immediately after the photo-shoot this participant liked the feeling that she had just been with someone (Rick) who was more encouraging and understanding than most people. Because of him she was able to forget about her reservations and pose for the pictures easily

- This participant commented that her feelings about the Positive Exposure photo-shoot experience had not changed over the course of the year following the photo-shoot, for it was one of the few experiences in her life in which she did not feel judged "[My feelings about the photo-shoot] have not changed. I feel that because you don't run into photographers that specialize in taking pictures of those who feel less perfect. Notice I didn't say we are less perfect, but simply not standard. We learn to feel less perfect through the years of teasing, and society making us feel uncomfortable."

- In the year after the photo-shoot, this participant's feelings about herself changed dramatically because of the birth of her son. She attributes her change in self-concept to "having a perfect beautiful baby boy. A model type of a son, has allowed me to acknowledge that while I may not be perfect on the outside, I am certainly perfect inside."

\section{DISCUSSION}

These four cases formally imply the potential long-term effects of Positive Exposure as an intervention. After participating in a professional photo shoot, the participants experienced their own inner and outer beauty. Positive Exposure's uplifting photographic images enabled our participants to define themselves, in some cases for the first time, by their strengths rather than their condition.

Positive Exposure, which includes Rick Guidotti's dynamic and 
compassionate personality, revitalized the participants' self-perception and enabled them to see the many ways in which they are attractive. As individuals participated in the photo-shoot, Rick typically perceives a change in them from feeling reticent and self-conscious to feeling confident. He describes the

\section{As individuals participated inthephoto-shoot, Rick typically perceives a change in them from feeling reticent and self- conscious tofeeling confident.}

very first person, a 17-year-old woman with albinism, who he photographed with Positive Exposure. "She walked into my studio with her shoulders hunched, head down, no eye contact, and offering only one-word answers to my questions. I began the photo shoot with the same energy and passion I instinctually had used on all my past models. Within moments, this beautiful girl placed her hands on her hips threw her shoulders back and raised her glorious head to the sky. Before my eyes and lens, she was empowered with a new sense of herself. She could see herself as a beautiful girl. This new vision of who she was amazing to experience!" Whether such positive feelings experienced both at the time of the photoshoot and thereafter can be sustained in a meaningful way is unknown. However,

\section{Whether such positive feelings experienced both at the time of the photo-shoot and thereafter can be sustained in a meaningful way is unknown}

these cases suggest that Positive Exposure promises affirming, lasting effects on self-concept and self-image.

Establishing a connection with an individual who may have a lower selfconcept or self-esteem related to physi- cal differences may be therapeutic in the sense that the individual is reminded that he or she is valued and valuable and has aspects of him or herself that make him or her attractive to others, making such feelings more salient. To have such feelings reinforced by the professional photographer may help them to become more consistently present in the lives of individuals with craniofacial differences. On the other hand, a professional photoshoot, even with as compassionate a photographer as Rick, is insufficient to instill a fundamental self-esteem that did not previously exist. One's self-image forms over many years and is influenced by parents, family values and upbringing, and inherent personality traits. For many, however, social stigmatization or shame can overshadow a positive selfconcept that may re-emerge within a trusting, caring, genuine and empathic interaction and preserved by the image captured in a photograph.

These four participants described how their newfound self-perceptions as attractive and confident individuals persist to this day, more than a year after their Positive Exposure photo-shoot experience. Each of the participants also commented on Rick Guidotti's personal photographic style as an important component of the photo-shoot experience. Rick apparently succeeded in helping participants realize aspects of their inner sense of self that they either did not have the opportunity or the confidence to expose and explore. In one case the participant found the photo-shoot experience sexually enlightening. These cases are testimony to the potential of Positive Exposure to help individuals tap into intimate feelings previously unexplored. Yet another reason for Rick's commitment to Positive Exposure came from a photo session with another young woman with albinism. After the shoot, she proclaimed, "I realize the hatred and abuse that I experience will never disappear but what has disappeared is the hatred I felt for myself."

In considering photo-shoots as a possible avenue through which to bolster self-esteem, self-image, and hopefulness, one cannot disentangle Rick
Guidotti from the experience of the photo-shoot itself. In fact, the primary intervention may be the individual's interaction with the photographer. Rick Guidotti's personality, enthusiasm, laughter, and goals for Positive Exposure may prove to be interventions in and of themselves.

\section{Strengths and Limitations}

The strength of these cases is to foster further research into the effectiveness of Positive Exposure as an innovative intervention. Including members of Forward Face and the Sturge-Weber Foundation in the parent study design, development, and analysis helped ensure that our study questions were relevant and appropriate for the challenges and life experiences encountered by participants. Support Group members actively provided input on the personal reflections, in what concepts seemed more salient to those with craniofacial conditions and in how participants will be recruited. In addition, results from this pilot effort can serve as a foundation to inform future research on this topic. Moreover, these cases focused on individuals with craniofacial differences in a positive way. This emphasis on the positive is a promising approach to future research within this population that is both lacking and advocated for in the craniofacial literature [Eiserman, 2001; Strauss, 2001].

The overall limitation of these cases is their preliminary nature. Participation depended upon self-selection. Individuals who elected not to complete the personal reflections might have different feelings and/or opinions about the impact of the intervention. Also, there was likely a selection bias in using a support group to recruit. These cases are reported as cursory, exploratory, and descriptive examples of the longer-term effects of Positive Exposure. We are currently conducting an ongoing mixed methods research study of the more immediate and short-term (6-month) outcomes of Positive Exposure. Alone these case studies are insufficient to suggest any conclusions. However, as a prelude to further research our 
qualitative findings offer a promising first glimpse at a unique and potentially powerful intervention to challenge stigma and encourage hopefulness for people with visible differences.

\section{ACKNOWLEDGMENTS}

We would like to thank Jodie Morrow and Dena Zuckerberg from Inner Faces for their enthusiasm and support during the initial stages of this endeavor. Most importantly, we thank the Inner Faces members who participated in this project. This research was supported in part by the Intramural Research Program of the National Human Genome Research Institute, National Institutes of Health.

\section{REFERENCES}

DeMarre L. 2004. Inner Essence: Photography and PhotoTherapy. www.inneressencephotography.com/phototherapy/index.html.
Dollinger SJ. 2002. Physical attractiveness, social connectedness, and individuality: An Autophotographic Study. J Soc Psychol 142:25-32.

Eiserman W. 2001. Unique outcomes and positive contributions associated with facial difference: Expanding research and practice. Cleft Palate Craniofac J 38:236-244.

Ellison MS. 2005. Anorexia and Photo Therapy. Suite $101 \mathrm{com}$.

Hagedorn M. 1990. Using photography with families of chronically ill children. In: Leininger $\mathrm{M}$, Watson J, editors. The caring imperative in education. New York, NY: National League for Nursing. p 227-233.

Highley BL, Ferentz T. 1989. The camera in nursing research and practice. In: Gilliss CL, Highley BL, Roberts BM, Martinson IM, editors. Toward a science of family nursing. Menlo Park, California: Addison-Welsley Publishing Company. p xxi-xxvii.

Jones B. 1996. 'Drop 'em Blossom'-clinical photography and patient dignity. J Audiov Media Med 19:85-86.

Kapp-Simon KA. 1995. Psychological interventions for the adolescent with cleft lip and palate. Cleft Palate Craniofac J 32:104-108.

Kapp-Simon KA, Simon DJ, Kristovich S. 1992. Self-perception, social skills, adjustment, and inhibition in young adolescents with craniofacial anomalies. Cleft Palate Craniofac J 29:352-356.
Kelton RW. 2001. Facing up to stigma: Workplace and personal strategies. Cleft Palate Craniofac J 38:245-247.

Phillips D. 1986. Photography's use as a metaphor of self with stabilized schizophrenic patients. Arts Psychother 13:9-16.

Pope AW, Ward J. 1997a. Factors associated with peer competence in preadolescents with craniofacial anomalies. J Pediatr Psychol 22: 455-469.

Pope AW, Ward J. 1997b. Self-perceived facial appearance and psychosocial adjustment in preadolescents with craniofacial anomalies. Cleft Palate Craniofac J 34:396401.

Sarwer DB, Bartlett SP, Whitaker LA, Paige KT, Pertschuk MJ, Wadden TA. 1999. Adult psychological functioning of individuals born with craniofacial anomalies. Plast Reconstr Surg 103:412-418.

Strauss RP. 2001. "Only skin deep": Health, resilience, and craniofacial care. Cleft Palate Craniofac J 38:226-230.

Weiser J. 1988. “See What I Mean?” photography as nonverbal communication in cross-cultural psychology. In: Poyatos F, editor. Cross-cultural perspectives in nonverbal communication. Toronto: C.J. Hogrefe. p 245-290.

Weiser J. 2005. The techniques of photoTherapy. www.phototherapy-centrecom/ five_techniques.htm. 